\title{
BRIDGING THE GAP BETWEEN SURVEYORS AND THE GEO-SPATIAL SOCIETY
}

\author{
H. Müller \\ Mainz University of Applied Sciences, Institute for Spatial Information and Surveying Technology (i3mainz), \\ Lucy-Hillebrand-Str. 2, D-55128 Mainz, Germany - hartmut.mueller@hs-mainz.de
}

KEY WORDS: Geospatial Information, Information Technology, Management, Surveyor, Geo-data Manager

\begin{abstract}
:
For many years FIG, the International Association of Surveyors, has been trying to bridge the gap between surveyors and the geospatial society as a whole, with the geospatial industries in particular. Traditionally the surveying profession contributed to the good of society by creating and maintaining highly precise and accurate geospatial data bases, based on an in-depth knowledge of spatial reference frameworks. Furthermore in many countries surveyors may be entitled to make decisions about land divisions and boundaries. By managing information spatially surveyors today develop into the role of geo-data managers, the longer the more. Job assignments in this context include data entry management, data and process quality management, design of formal and informal systems, information management, consultancy, land management, all that in close cooperation with many different stakeholders. Future tasks will include the integration of geospatial information into e-government and e-commerce systems. The list of professional tasks underpins the capabilities of surveyors to contribute to a high quality geospatial data and information management. In that way modern surveyors support the needs of a geo-spatial society. The paper discusses several approaches to define the role of the surveyor within the modern geospatial society.
\end{abstract}

\section{INTRODUCTION}

Surveying is a profession with a long history. Since ancient times surveyors were involved in measuring and depicting the earth's surface with the natural, built and planned environments. Driven by the advances of technologies including computing, communications and geospatial data processing, the recent decades have shown increased demand and importance on accurate, timely and user-friendly geospatial information (Fosburgh, 2011, see also Seedat, 2014). As a result, the surveyor's role today includes communication with various stakeholders including engineers, architects, planners, local government, landowners, utility service providers and others. The surveyor's new function has transformed to that of geo-data manager, creating, verifying or modifying digital data sources and design models of various kind. Surveyors have to play an active part in GIS activities, such as creating, filling and maintaining a GIS, and using it as a tool to manage the natural and built environment as well as the cadastre. The surveyor's activities in GIS data collection are measurements, but also collection and management of attributes about the elements they geo-locate. Most likely technology will play an even greater role in the future. Field systems can be coupled with mobile phone and Internet access, cloud computing and web-based geodatabases. In that way information and techniques can be combined to an extent never before thought. Traditionally, surveyors are well educated in terms of theory, mathematics, principles of redundancy and quality assurance. The opportunity for the surveyor to provide services that enable best practices in data collection and quality assurance is still present today. More than that, the deeper understanding of processes is even more important in times where the surveying equipment has become so user-friendly that the technology in most cases can be used by non-surveyors. The ability to plan with a GIS and to use it to understand ongoing processes is a huge opportunity for a geodata manager. The surveyor of the future is able to extract new information and knowledge from existing datasets and to provide it to land managers. The society insists on speedier data collection and generation of useful information. Therefore, it becomes imperative to use analysis tools for managing, verifying and interpreting vast data volumes, data collection for populating and updating the GIS, quality assurance and data management and analysis. Communicating the information to the users will be another key challenge. Surveyors should be prepared to present information using a variety of media including static and dynamic visualizations. The surveyor of the future must demonstrate a broad set of multidisciplinary skills. $\mathrm{He}$ or she must have the skills to navigate various cultural and technical barriers as well as to communicate across different knowledge areas, disciplines and customary local processes. The world today has evolved from data collection into geo-data management and information and knowledge extraction. Individual surveyors, and the societies they belong to, must collaborate with academia, government and industry to achieve common goals and benefits. Fosburgh, 2011 states that surveyors are the geo-data managers of the future--and that tomorrow's professionals are prepared for the challenge through education, training and professional development. In the following sections the positions of FIG, the International Federation of Surveyors and of DVW, German Society of Geodesy, Geoinformation and Land Management in this debate will be reported.

\section{FIG DEFINITION OF THE FUNCTIONS OF THE SURVEYOR}

FIG is a federation of national associations and represents the surveying disciplines. Its aim is to ensure that the disciplines of surveying and all who practise them meet the needs of the markets and communities that they serve. It realises its aim to ensure that the disciplines of surveying meet the needs of markets and communities by promoting the practice of the profession and encouraging the development of professional standards. In 2004, the FIG General Assembly adopted its own definition of the functions of the surveyor (FIG, 2004). 


\subsection{The official FIG definition}

2.1.1 Executive summary: A surveyor is a professional person with the academic qualifications and technical expertise to conduct one, or more, of the following activities;

- to determine, measure and represent land, three-dimensional objects, point-fields and trajectories;

- to assemble and interpret land and geographically related information,

- to use that information for the planning and efficient administration of the land, the sea and any structures thereon; and,

- to conduct research into the above practices and to develop them.

2.1.2 Detailed functions: The surveyor's professional tasks may involve one or more of the following activities which may occur either on, above or below the surface of the land or the sea and may be carried out in association with other professionals.

1. The determination of the size and shape of the earth and the measurement of all data needed to define the size, position, shape and contour of any part of the earth and monitoring any change therein.

2. The positioning of objects in space and time as well as the positioning and monitoring of physical features, structures and engineering works on, above or below the surface of the earth.

3. The development, testing and calibration of sensors, instruments and systems for the above-mentioned purposes and for other surveying purposes.

4. The acquisition and use of spatial information from close range, aerial and satellite imagery and the automation of these processes.

5. The determination of the position of the boundaries of public or private land, including national and international boundaries, and the registration of those lands with the appropriate authorities.

6. The design, establishment and administration of geographic information systems (GIS) and the collection, storage, analysis, management, display and dissemination of data.

7. The analysis, interpretation and integration of spatial objects and phenomena in GIS, including the visualisation and communication of such data in maps, models and mobile digital devices.

8. The study of the natural and social environment, the measurement of land and marine resources and the use of such data in the planning of development in urban, rural and regional areas.

9. The planning, development and redevelopment of property, whether urban or rural and whether land or buildings.

10. The assessment of value and the management of property, whether urban or rural and whether land or buildings.
11. The planning, measurement and management of construction works, including the estimation of costs.

In the application of the foregoing activities surveyors take into account the relevant legal, economic, environmental and social aspects affecting each project.

\subsection{Recent developments in FIG}

The definition reported in Section 2.1 reflects to a great extent the traditional professional field of surveyors. At the FIG Working Week in Rome, Italy, (May 6-10, 2012) FIG started to broaden its view towards a wider definition, described by the term 'Surveyor 2.0' (Schennach et al., 2012). Teo CheeHai, past president of FIG, has noticed that 'the role of the surveyor is evolving from a professional who used to be viewed as a "measurer" to a professional who measures, models, and manages'.

ACSM, 2012 notes rapid technological changes are taking place in a challenging economic and political landscape. Online and mobile services, such as online maps and smartphone apps, are stimulating an increasing interest and use of geospatial information. Citizen- centric service delivery is crucial. In this interview the president argues, that surveyors 'will be required to embrace open standards; be inclusive, learn to incorporate volunteered information; ensure interoperability of systems, institutions and legislation; have a culture of collaboration and sharing to avoid duplication; develop enabling platforms in order to deliver knowledge derived from data of different scales and origins in the form of "actionable" information'. In an ongoing discussion FIG now promotes the "Surveyor 2.0 model' (Fig. 1).
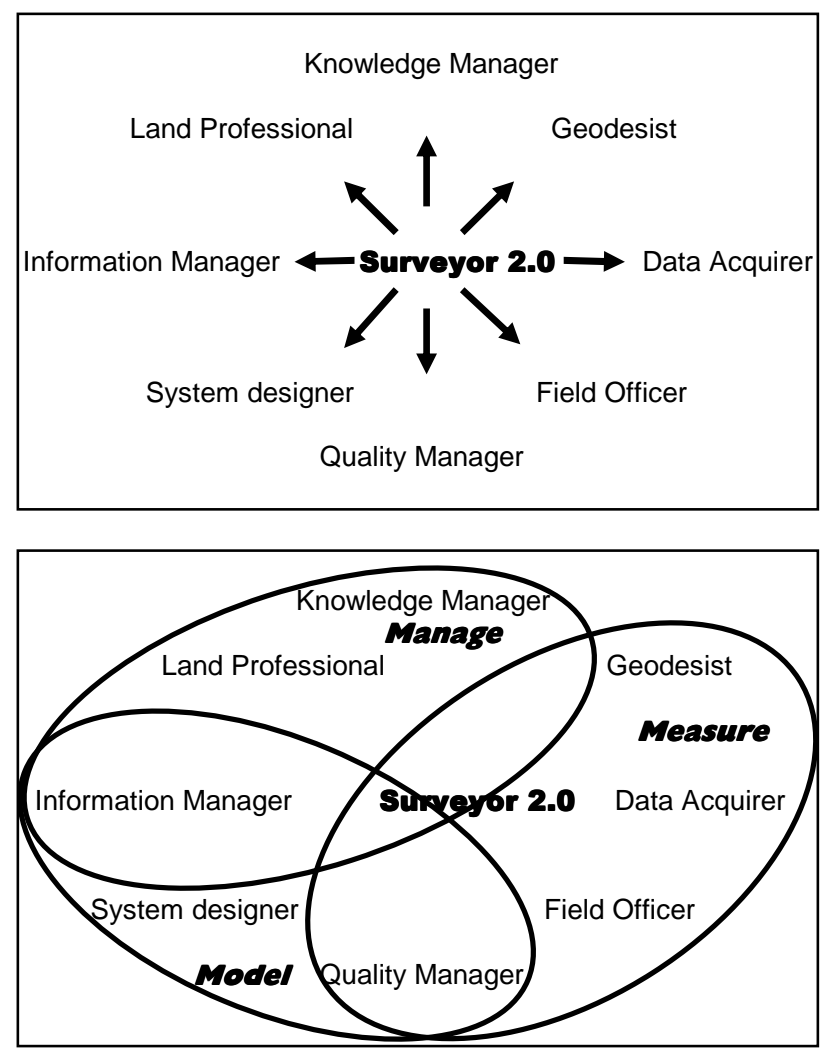

Figure 1. The Surveyor 2.0 Model, adapted from G. Schennach et al. (2012) 
Here, the surveyor is described in the triad Manage-ModelMeasure. Such a definition seems to largely overlap with the definition of a geo-data manager (see the following section).

\section{THE PROFILE OF A GEO-DATA MANAGER}

Recently, in an ongoing process the Working Group 'Geoinformation and Geo-data Management' of the German DVW, Society for Geodesy, Geoinformation and Land Management worked on the definition of a geo-data manager's functions. In the following sections some intermediate results of the work will be reported.

\subsection{The framework of geo-data management}

Geo-data management is a cross-cutting task of Geodesy and Geoinformatics comprising three core areas of expertise (Fig. 2):

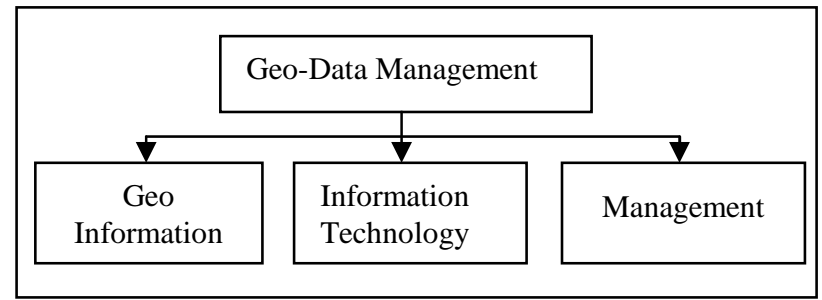

Figure 2. The triad of Geo-data Management,

(German DVW Working Group, 2016, unpublished)

1. Geoinformation; in particular application-specific recording, quality assurance, analysis and presentation of spatial objects based on the geodetic spatial reference of position, height and gravity (Geo skills),

2. Information technology; in particular technology of data and systems, design and implementation of technical solutions, development of service-oriented architectures and systems, modeling, coding and automation of data exploration, by methods of information and communication technology (IT skills)

3. Management; in particular strategic development, structuring, coordination and control of processes, by communication with all involved parties (management skills)

\subsection{The individual profile of a geo-data manager}

Depending on the individual field of work a geo-data manager may face a considerable range of required skills in the three core areas of expertise Geoinformation, Information technology, Management. The full requirements profile of a geo-data manager comprises the following components

3.2.1 Professional skills: the following section describes the full list of currently identified professional skills of a geo-data Manager.

1. Establishment of a framework for the comprehensive use of geospatial data. The geo-data manager coordinates development and operation of spatial data infrastructures to provide spatial data from different sources by interoperable spatial data services. He or she moderates the interests of providers and users and develops the legal, professional, technical and organizational framework for the comprehensive use of spatial data. He or she develops application-driven specifications for data provision via standard based services. He or she monitors compliance with the specifications to ensure the multidisciplinary usability of spatial data (interoperability).

2 Identification of spatial data needs, as-is analysis and data collection. The geo-data Manager identifies and analyzes the user requirements (internal vs. external users) in the context of specific applications. He or she gets an overview of available data (inventory analysis of in-house offers against third party offers) and evaluates the potential benefit of spatial data sets for specific application areas, in cooperation with experts from other disciplines. He or she procures appropriate spatial data obtained by third parties and clarifies access, usage and pricing conditions.

3 Data processing, administration, management and updating. The geo-data Manager collects existing data, transforms them into consistent data formats, integrates them geometrically and semantically into a Geographic Information System (GIS), prepares them to meet individual professional requirements, updates and maintains them. He or she accomplishes these tasks within an established framework and provides the necessary transformation rules, exchange formats and meta data.

4 Application-specific exploration of spatial data, process integration and information management. By analyzing and redesigning processes and by developing an adapted role model the geo-data manager supports the integration of data products into an existing environment of administrative and business processes. To generate new information he or she designs and implements automated analysis of combinations of spatial data from different sources (exploration of Big Geo-Data). He or she prepares the results clearly. He or she is involved in collaboration processes with other disciplines to interpret spatial data appropriately. He or she ensures that the necessary information is generated in a user-centric form.

5 Design of new data products. On the basis of needs assessment and inventory analysis the geo-data manager designs new data products for specific applications while also taking into account future demands of stakeholders. To achieve that, he or she creates conceptual application schemes in communication with other specialists and IT experts data. Following his or her professional expertise the coding for the data transfer in appropriate data formats will be performed (external schema). He or she provides support for the implementation of the data management policy

6 Development of production methods. The geo-data manager identifies appropriate methods for the geodetic collection of the product data (initial recording vs. updating, such as terrestrial surveying, remote sensing, crowdsourcing, mobile mapping) and adapts them to the technical requirements. He or she coordinates the interaction of different partners to create novel data products. He or she develops quality assurance procedures to guarantee for the long-term professional and technical product quality which meets the user requirements.

7 Definition of the general data production environment, particularly for marketing and sales activities. The geo-data manager determines the framework for spatial data marketing and sales. He or she determines product names and product specifications, takes into consideration any access restrictions (copyright, security, privacy) and other obligations determined 
by legal regulations. He or she defines the usage and payment terms, targeted markets, distribution channels, product availability, performance and provided capacity of the data production process. He or she creates the documentation of product specification, for in house use and for publication in metadata catalogs provided within spatial data infrastructures.

8 Implementation and operation of an IT infrastructure to manage spatial data (GeoIT infrastructure). The geo-data manager identifies data volumes, access rights, facades and role models for the use of spatial data in an organization. Following the trends of the mainstream IT he or she designs a standards based architecture of an appropriate GeoIT infrastructure. The design of such architecture includes the system design of network, servers, database management system, application technology, referring to modern IT concepts (SOA, ROA, etc.) including operation and safety concepts (ITSM). He or she makes decisions on the necessary components of the GeoIT infrastructure, such as GIS, software / hardware and other technical core components (geo portals, geo catalogues, etc.).

9 Design and development of services and applications. Following the identified and adopted user requirements the geodata manager develops spatial data processing services to facilitate the implementation of user-specific applications (desktop, web, mobile) such as specialized geographic information systems vs. mainstream e-government applications and other procedures.

10 Quality management and quality control. The geo-data manager designs and implements the user oriented framework for quality assurance of the spatial data and of the derived products. He installs mechanisms to monitor the entire process chain in order to ensure the spatial data product quality.

11 Basic, advanced and further training. The geo-data manager provides basic, advanced and further user training.

3.2.2 Methodological and social skills: the following section describes the most important identified methodological and social skills of a geo-data Manager.

1 Project management. The geo-data manager is involved in award procedures, support, monitoring, controlling, resource management (human, technical, financial), process documentation, reporting, profitability analysis, decision management, and operational management of spatial data projects and products.

2 Coordination. The geo-data manager coordinates and controls all spatial data related processes in cooperation with all stakeholders. He or she is the link between the technical and administrative management levels. He or she moderates and supports the cooperation of different stakeholders and ensures transparency in the project consortium (information sharing).

3 Moderation. The geo-data manager moderates complex processes in a highly interdisciplinary context. Fast-moving developments in the digital world continuously generate processes of change. Different understanding of the same topics across different professional disciplines has to be considered. Reservations with regard to Geo-IT infrastructures are still present. In this environment the geo-data manager has to be a conflict manager who has pronounced negotiation skills.

\section{CONCLUSIONS}

In the previous sections it was shown in which ways today's surveyors can take action for the benefit of a modern geospatial society. Job assignments in this context include technical tasks such as data entry management of highly heterogeneous spatial data created by classical surveying activities, mobile mapping, aerial and satellite imagery, crowdsourcing activities, and others; information management, consisting of data integration and transformation, of data integration from different sources, general IT, web technologies; quality management, including responsibility for the accuracy of attributes and relationships of data, for accuracy assessment, for completeness and reliability of data, for certification; system design of formal and informal systems for security of land tenure, for creation and maintenance of code lists, for spatial data infrastructures, for 2D and 3D data management, workflows, business processes. In such a highly interdisciplinary working environment nontechnical skills are required for interpersonal communication, including responsibility for participation management, handling of appeal procedures, and conflict resolution. Consultancy for urban and rural development, reorganization, real estate issues, spatial planning may be further components of the professional work. Future tasks include the integration of geospatial information into e-government and e-commerce systems. Surveyors have the potential to perform high quality geospatial data and information management. If the surveying profession takes the plunge into the new fields the gap between surveyors and the geospatial society can be closed.

\section{ACKNOWLEDGEMENTS}

Decisive contributions of the members of the German Working Group André Caffier, Dieter Heß, Martin Scheu, Markus Seifert, Robert Seuß to this work are well acknowledged.

\section{REFERENCES}

Schennach, G., Lemmen, C., Villikka, M., 2012. Be part of the solution, not the problem! FIG Working Week, Rome, Italy. GIM International, July 2012, pp 33-35. https://www.fig.net/resources/articles_about_fig/giminternational/2012_07_gim_report.pdf (10 May 2016).

FIG, 2004. FIG Definition of the functions of the surveyor https://www.fig.net/about/general/definition/definition.pdf (10 May 2016).

ACSM, 2012. FIG looks to surveyor 2.0, ACSM Bulletin June 2012, pp 31-32. http://www.multibriefs.com/briefs/nsps/ acsm257p31.pdf (10 May 2016).

Sass, J., 2012. The surveyor's role as geo-data manager, Machine Control Magazine, Vol. 2 No. 3, 2012, Spatial Media, pp 45-47, http://machinecontrolmagazine.com/ PDF/MachineControlMagazine_SassSurveyor2.0_Vol2No3.pdf (10 May 2016).

Seedat, M., 2014. The surveyor's role as geo-data manager, http://www.durban.gov.za/City_Services/engineering\%20unit/S urveying_Land_Information/Documents/TheRole_of_Surveyor _as_a_GeoData_Manager.pdf (10 May 2016)

Fosburgh, B., 2011. The evolution of the geo-data Manager, http://www.pobonline.com/articles/95617-the-evolution-of-thegeo-data (10 May 2016). 